\title{
Improvements in neuroelectrophysiological and rear limb functions in rats with spinal cord injury after Schwann cell transplantation in combination with a $\mathrm{C5a}$ receptor antagonist
}

\author{
S.-Q. Zhang' ${ }^{1}$ M.-F. Wu², C.-G. Peng ${ }^{2}$, Y. Lv², D.-K. Wu², J. Liu³ and Q. Yang ${ }^{4}$ \\ 1Department of Orthopedics, Tianjin Nankai Hospital, Tianjin, China \\ ${ }^{2}$ Department of Orthopedics, China-Japan Union Hospital, Jilin University, \\ Changchun, China \\ ${ }^{3}$ Center for Hand-foot Surgery and Reparative \& Reconstructive Surgery, \\ Orthopaedic Hospital of the Second Hospital of Jilin University, Changchun, China \\ ${ }^{4}$ Department of Obstetrics and Gynecology, China-Japan Union Hospital, \\ Jilin University, Changchun, China \\ Corresponding author: J. Liu \\ E-mail: yangqi_66@yeah.net \\ Genet. Mol. Res. 14 (4): 15158-15168 (2015) \\ Received April 23, 2015 \\ Accepted July 22, 2015 \\ Published November 25, 2015 \\ DOI http://dx.doi.org/10.4238/2015.November.25.4
}

ABSTRACT. We measured the effect of Schwann cell transplantation and complement factor $5 \mathrm{a}(\mathrm{C} 5 \mathrm{a})$ receptor antagonist on nerve function recovery in rats with spinal cord injury. Experimental spinal cord injury was induced in eighty Wistar rats and these were randomly divided into four treatment groups: culture medium and saline injection (control group), Schwann cell injection (cell transplantation group), C5a receptor antagonist injection (C5a receptor antagonist group), and both Schwann cell and C5a receptor antagonist injections (combination group). Rear limb functional recovery was assessed 1, 2, 4, 6, and 8 weeks after the spinal cord injury with the 
tilt table test and the Basso, Beattie, Bresnahan scale. Sex-determining region $Y(S R Y)$ gene expression was measured at week 4 and horseradish peroxidase (HRP) labeling was used at week 8 to further assess the recovery of neuroelectrophysiological functions. The rear limb functional assessment showed that the combination group had better outcomes than the cell transplantation and C5a receptor antagonist groups. All treatment groups had better outcomes than control. Only the cell transplantation and combination groups showed SRY expression. The number of HRP-positive nerve fibers in the different groups ranked as follows: combination group > cell transplantation and C5a receptor antagonist $>$ control. The refractory period and amplitude of the induced potential in the combination group were significantly greater than in the other three groups. These results suggest that the combination of Schwann cell transplantation and the C5a receptor antagonist enhances the regeneration of injured synapses and improves limb function and electrophysiology.

Key words: Schwann cell; C5a receptor antagonist; Spinal cord injury; Cell transplantation

\section{INTRODUCTION}

Human development and the advancement in transportation technologies have led to an increase in the rate of spinal cord injuries. It has now become a condition with one of the highest mortality rates (Braisted, 2000; De Vries and Cooper, 2008). Enhancing nerve regeneration and functional recovery after spinal cord injury is an ongoing medical challenge. Conventional therapies including surgeries, medications, and physical therapy remain ineffective in curing most spinal cord injuries (Fehlings and Sekhon, 2001; Chu et al., 2007; Haku et al., 2008; Weaver et al., 2009).

The anaphylatoxin complement factor $5 \mathrm{a}(\mathrm{C} 5 \mathrm{a})$ is the product of complement system activation and is an important chemokine mediator performing key roles in the pathological processes of spinal cord injury. C5a receptor antagonists effectively block this process. Another recently developed treatment consisting of Schwann cell transplantation has also been shown to enhance functional recovery after spinal cord injury (Pearse et al., 2007; Papastefanaki et al., 2007). In the current study, we combined C5a receptor antagonist treatment with Schwann cell transplantation and measured the recovery of nerve function after spinal cord injury.

\section{MATERIAL AND METHODS}

\section{Materials}

Eight male and eighty female healthy Wistar rats (200-250 g) were purchased from the animal laboratory of the Chinese Academy of Medical Science [animal quality certificate No.: SCXK (Tianjin) 20050076]. C5a receptor antagonist AcF - [OP (D - Cha) WR] (PMX53) (1.0 mg/kg, synthesized from Shanghai Jill Biochemical Co., LTD). All procedures complied with the standards of animal ethics as established by The Ministry of Science and Technology of the People's Republic of China. Guidance Suggestions for the Care and Use of Laboratory Animals. 


\section{Experimental procedure}

\section{In vitro culture and myelin basic protein (MBP) immunofluorescence detection of Schwann cells}

As described in a previous study (Wan et al., 2003), the sciatic nerve was isolated using a microscope under sterile conditions, digested with a mixture of trypsin $(2.5 \mathrm{~g} / \mathrm{L})$ and collagenase $(2 \mathrm{~g} / \mathrm{L})$ for $40 \mathrm{~min}$, and centrifuged for $5 \mathrm{~min}$ at $1000 \mathrm{rpm}$. Cells were cultured in Dulbecco's modified Eagle's medium/F12 medium containing 10\% fetal bovine serum in an incubator at $37^{\circ} \mathrm{C}$ with $5 \% \mathrm{CO}_{2}$. After incubation for $30 \mathrm{~min}$, a differential adhesion method was used to remove fibroblasts; $100 \mu \mathrm{L}$ cytarabine (Ara-C, $5-10 \mathrm{mM}$ ) was added $24 \mathrm{~h}$ later to kill the remaining fibroblasts. Fourth passage Schwann cells were cultured on cover slips for 48 $\mathrm{h}$, washed three times with phosphate-buffered saline (PBS), and fixed with paraformaldehyde solution $(40 \mathrm{~g} / \mathrm{L}, \mathrm{pH} 7.4)$ at room temperature for $20 \mathrm{~min}$. Cells were washed with PBS three times and incubated with primary anti-MBP antibody at $4^{\circ} \mathrm{C}$ overnight in a wet box. The samples were washed three times with PBS, incubated with secondary antibody for $2 \mathrm{~h}$ at $37^{\circ} \mathrm{C}$, stained with 4'-6-diamidino-2-phenylindole (DAPI, 1:500, Sigma, Louis, MO, USA), and then incubated for $10 \mathrm{~h}$. After three more PBS washes, the samples were mounted and sealed on the slides for microscopic analysis (OLYMPUS IX71, Olympus Optical Co., Ltd Tokyo, Japan).

\section{Establishment of the animal model}

Eighty female Wistar rats weighing 200-250 g were maintained in the lab for 2 weeks. On the day of surgery, the rats were anesthetized with ketamine $(25 \mathrm{~g} / \mathrm{L})$ injected intraperitoneally at a dose of $20 \mathrm{mg} / \mathrm{kg}$ and fixed in the prone position on the surgery table. The hair on the back was removed and an incision was made in the middle of the back around the spinous process T8-9 in order to expose T7-10 and the vertebral lamina. The T8-9 spinous process and part of the vertebral lamina were cut to expose the spinal cord tissue in the target injury area. According to the modified Allen punch method (Young, 2002), a 10-g weight was dropped from a height of $2.5 \mathrm{~cm}$ onto the spinal cord tissue. A tail spasm followed by rear limb paralysis indicated the success of the spinal cord injury model. The incision area was washed with penicillin saline and sutured. The rat was then massaged on the abdomen to facilitate micturition.

\section{Experimental groups}

Rats were randomly divided into four groups (20 rats per group). The following treatments were given $6 \mathrm{~h}$ after the injury: 1) the blank control group received $1 \mathrm{~mL}$ culture medium by caudal vein injection and saline solution $(10 \mathrm{~mL} / \mathrm{kg})$ by intraperitoneal injection, 2) the cell transplantation group received $1 \mathrm{~mL}$ Schwann cells $\left(3 \times 10^{6}\right)$ injected through the caudal vein, 3) the C5a receptor antagonist group received a C5a receptor antagonist by intraperitoneal injection at $6 \mathrm{~h}$ and at $24 \mathrm{~h}$ after the injury (Finch et al., 1999), and 4) the combination group received Schwann cells $\left(3 \times 10^{6}\right)$ injected through the caudal vein at $6 \mathrm{~h}$ and a C5a receptor antagonist by intraperitoneal injection at $6 \mathrm{~h}$ and $24 \mathrm{~h}$ after the injury. 


\section{Rear limb motor function assessment}

The rear limb motor function of all rats was assessed using the tilt table test and the modified Tarlov rating scale before the injury and 1, 2, 4, 6, and 8 weeks after the injury. In the tilt table test, the rat was placed on the modified Rivlin tilt table horizontally with its head facing right. The table was tilted from the horizontal position $\left(0^{\circ}\right)$ gradually. The largest angle at which the animal could remain on the table was recorded. The test was repeated three times and an average value was calculated.

The Basso-Beattle-Bresnahan (BBB) motor function evaluation test (Pallini et al., 2005) was used to evaluate motor function in all groups in a double-blinded manner at 1, 2, 4, 6, 8, and 10 weeks after the injury. Each animal was assessed six times and the average score was used as the result.

\section{Polymerase chain reaction (PCR) for the sex-determining region $Y(S R Y)$ gene}

Four weeks after the injury, eight rats from each group were randomly chosen and anesthetized with pelltobarbitalum natricum $(20 \mathrm{~g} / \mathrm{L})$ by intraperitoneal injection. The chest was opened and a perfusion tube was inserted into the ascending aorta through the left ventricle. The right atrium was slit to allow drainage and a constant-speed perfusion of $200 \mathrm{~mL}$ iced saline was administered through the perfusion tube. When the liquid from the right atrium became colorless, the spinal cord tissue $(1 \mathrm{~cm})$ containing the injury was harvested. DNA was extracted by using a SRY - PCR kit (Shanghai generay Biological Technology Co., Ltd., china) and then stored. The rat SRY gene primers F: 5'-CTG GCT CTG CTC CTA CCT-3' and R: 5'-GCT GTT TGC TGC CTT TGA3' were used. The PCR mix contained $1.0 \mu \mathrm{L}$ DNA, $0.2 \mathrm{mM}$ dNTPs, $22.0 \mathrm{mM} \mathrm{MgCl}, 3.0 \mu \mathrm{L} 10 \mathrm{X}$ buffer, $1 \mu \mathrm{L}$ Taq DNA polymerase, $0.5 \mu \mathrm{M}$ of each primer, and deionized water to a total volume of $30 \mu \mathrm{L}$. Cycle parameters used were pre-denaturation for $5 \mathrm{~min}$ at $95^{\circ} \mathrm{C}, 32$ cycles of denaturation for $30 \mathrm{~s}$ at $94^{\circ} \mathrm{C}$, annealing for $45 \mathrm{~s}$ at $54^{\circ} \mathrm{C}$, elongation for $50 \mathrm{~s}$ at $72^{\circ} \mathrm{C}$, and a final elongation for $7 \mathrm{~min}$ at $72^{\circ} \mathrm{C}$. Reaction products were separated with $2 \%$ agarose gel electrophoresis and stained with ethidium bromide. The Gel Doc200 gel documentation apparatus was used to take pictures. The expected product was 325 base pairs.

\section{Somatosensory-evoked potential (SEP) and motor-evoked potential (MEP) measurement}

Eight weeks after the injury, seven rats from each group were selected and the SEP and MEP were measured using a KEYPOINT 4 Evoked Potential Response Unit as previously described (Albin and Mink, 2006). The animals were anesthetized with $10 \%$ chloral hydrate injected intraperitoneally and placed in a horizontal position with the stimulation electrode stabilized on the rear limbs. Recording electrodes were placed at the intersection of the coronal and sagittal sutures under the scalp (somatosensory cortex of the rear limbs), and reference electrodes were placed $0.5 \mathrm{~cm}$ behind these sutures. Stimulation was conducted to trigger light rear limb spams by direct current square pulses with a current intensity of 5-15 mA, wavelength of $0.2 \mathrm{~ms}$, frequency of 3 $\mathrm{Hz}$, and superposition of 50-60. The latency and amplitude changes of the SEP were recorded to observe the recovery of neuroelectrophysiological functions in the different treatment groups. For MEP measurements, the needle electrode was placed $2 \mathrm{~mm}$ before the top coronal suture and 2 
$\mathrm{mm}$ anterior the sagittal suture under the scalp (motor cortex area). Stimulation was conducted at an intensity of $40 \mathrm{~mA}$, wavelength of $0.1 \mathrm{~ms}$, frequency of $1 \mathrm{~Hz}$ and superposition 300-500, scan speed of $5 \mathrm{~ms} / \mathrm{D}$, and a sensitivity $5 \mu \mathrm{V} / \mathrm{D}$ ( $\mathrm{D}=\mathrm{DIV}$, DIV is the meaning of each lattice instrument scales). The latency and amplitude changes for the MEP were recorded.

\section{HRP retrograde neural tracing}

Two rats from each group were randomly selected at 8 weeks post-treatment. The animals were anesthetized and the spinal cord was exposed. Saline-dissolved HRP $(50 \% ; 1 \mu L)$ was injected at a speed of $0.1 \mu \mathrm{L} / 10$ min spreading to the posterior tissue of spinal cord injury using a needle inserted $1 \mathrm{~mm}$ from the middle vein of T12 at a depth of $1.5 \mathrm{~mm}$. The needle was kept inserted for $15 \mathrm{~min}$. Three days after the procedure, the animals were anesthetized with chloral hydrate and transcardially perfused with paraformaldehyde (40 g/L). The spinal cord (T3-T11) was removed and submerged in a $30 \%$ sugar solution at $4^{\circ} \mathrm{C}$ for $20 \mathrm{~h}$. It was then cut into $5-\mu \mathrm{m}$-thick frozen sections and stained with diaminobenzidine (DAB). The HRP-positive nerve fibers in the injured region were counted under the microscope. Ten sections from each group at each time point were randomly selected for counting.

\section{Statistical analysis}

The SAS 8.0 software was used for statistical analysis. Measured results are reported as means \pm standard error. Data was analyzed using repeated-measures ANOVA or $t$-tests. A significance level of $\mathrm{P}<0.05$ was used to establish differences between groups.

\section{RESULTS}

\section{Schwann cell observations}

Inverted phase-contrast microscopy showed that cells covered the flask bottom after 5-6 days in culture and that most were Schwann cells with only a few fibroblasts. After purification, Schwann cells comprised over $95 \%$ of all cells. The cells were narrow, long, and spindle shape with a small nucleus and secretion products surrounding them (Figure 1). MBP immunofluorescence images showed that the cytoplasm of Schwann cells and their axons were stained green with the antibody staining, whereas the nuclei of Schwann cells and fibroblasts were stained blue by DAPI staining. The cytoplasm of fibroblast cells remained colorless. It was therefore possible to approximate the proportion of Schwann cells in the culture. Figure 2 shows a representative picture of MBP fluorescence in Schwann cells clearly depicting their narrow shape and small nucleus.

\section{Rear limb motor function evaluation after transplantation}

The results of the tilt table test and modified BBB rating are shown in Tables 1 and 2 . Starting at 4 weeks post-treatment, the rear limb function in the combination group was significantly improved compared with the control group. Both the cell transplantation group and the C5a antagonist group showed significant improvements in rear limb function as compared with the control group. 


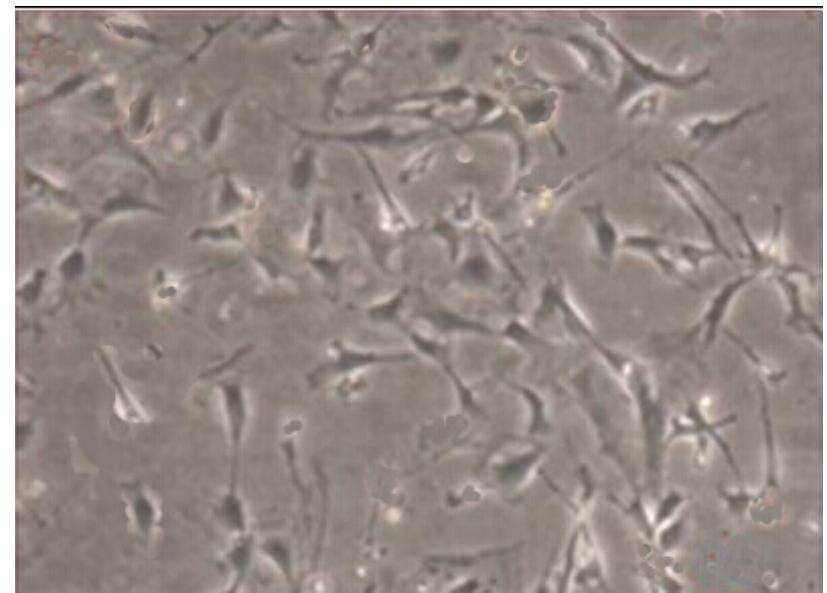

Figure 1. As seen with inverted phase-contrast microscopy (40X), Schwann cells are aligned tightly with a spindle shape.

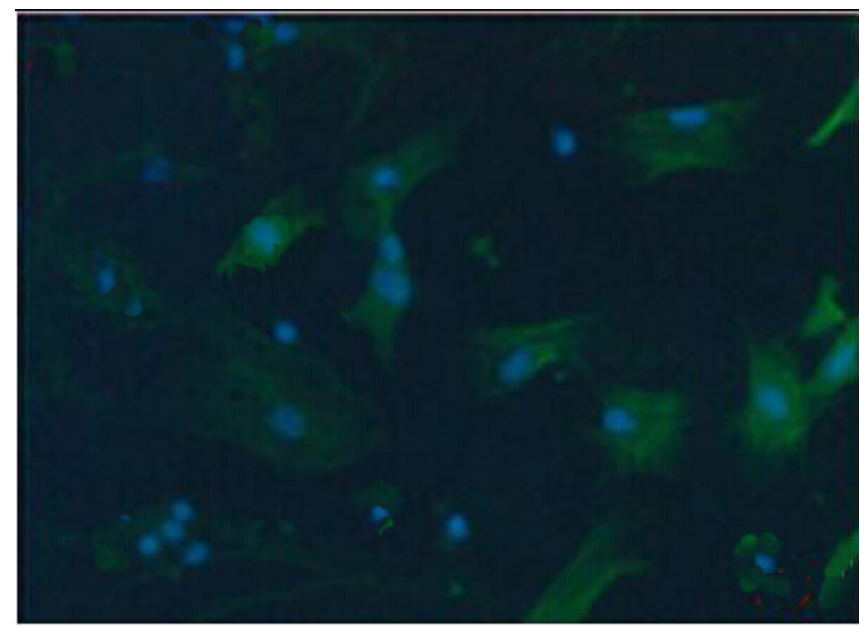

Figure 2. MBP immunofluorescence image of Schwann cells (40X) stained with anti-MBP antibody and DAPI.

Table 1. Results of the inclined plane test in rats in each group after transplantation (degrees \pm error).

\begin{tabular}{lccccc}
\hline Treatment group & 1 week & 2 weeks & 4 weeks & 6 weeks & 8 weeks \\
\hline Control & $0.54 \pm 0.13$ & $1.46 \pm 0.24$ & $4.98 \pm 0.69$ & $6.46 \pm 0.76$ & $7.13 \pm 0.78$ \\
Cell transplantation & $0.54 \pm 0.15$ & $1.64 \pm 0.29$ & $5.47 \pm 0.89^{\#}$ & $8.74 \pm 0.65^{\#}$ & $9.24 \pm 1.21^{\#}$ \\
C5a receptor antagonist & $0.54 \pm 0.14$ & $1.65 \pm 0.31$ & $5.46 \pm 0.97^{\#}$ & $8.75 \pm 0.89^{\#}$ & $9.26 \pm 1.28^{\#}$ \\
Joint group & $0.53 \pm 0.12$ & $1.77 \pm 0.34$ & $6.65 \pm 1.02^{\star}$ & $9.98 \pm 0.74 \star$ & $12.75 \pm 1.37^{\star}$ \\
\hline
\end{tabular}

Compared with control group: ${ }^{\mathrm{P}}<0.05 ; \boldsymbol{\Delta} \mathrm{P}<0.01$.

\section{SRY PCR}

As shown in Figure 3, both the cell transplantation group and the combination group 
expressed the SRY gene 4 weeks after the injury, suggesting that the transplanted Schwann cells survived and participated in the repair of injured spinal cord. The C5a antagonist and control groups showed no SRY expression.

Table 2. Result of the BBB scale in each group after transplantation (degrees \pm error).
\begin{tabular}{lccccc}
\hline Treatment group & 1 week & 2 weeks & 4 weeks & 6 weeks & 8 weeks \\
\hline Control & $11.0 \pm 0.5$ & $12.3 \pm 0.6$ & $15.8 \pm 0.6$ & $19.4 \pm 1.6$ & $22.1 \pm 1.1$ \\
Cell transplantation & $11.3 \pm 0.7$ & $12.6 \pm 0.7$ & $20.6 \pm 1.3^{\#}$ & $23.2 \pm 1.5^{\#}$ & $25.3^{\#} 1.2^{\#}$ \\
C5a receptor antagonist & $11.2 \pm 0.6$ & $12.7 \pm 0.8$ & $20.7 \pm 1.2^{\#}$ & $22.9 \pm 1.7^{\#}$ & $25.2 \pm 1.3^{\#}$ \\
Joint Group & $11.4 \pm 0.7$ & $14.8 \pm 0.9$ & $24.9 \pm 1.4^{\star}$ & $27.8 \pm 1.4^{\star}$ & $29.8 \pm 1.7^{\star}$ \\
\hline
\end{tabular}

Compared with control group: ${ }^{*} \mathrm{P}<0.05 ;{ }^{\wedge} \mathrm{P}<0.01$.

\section{HRP retrograde neural tracing}

After DAB staining, the HRP injection created a deeply colored area in the center of neurons that faded into the surroundings. In rats of the control group, 2 days after the HRP injection from the intumescentia cervicalis and because of HRP retrograde transport, a few HRP-positive nerve fibers were observed above T8 (Figure 4A). HRP-positive nerve fibers were also observed in the transplantation and $\mathrm{C} 5 \mathrm{a}$ antagonist groups, where they were more numerous than in the control group (Figures 4B and 4C). The combination group had the most HRP-positive fibers (Figure 4D). Quantification of HRP-positive nerve fibers in injured spinal cord for each group is shown in Figure 5. At 8 weeks post-injury, both the combination group and the control group showed a significant difference in the number HRP-positive nerve fibers compared with the transplantation and the C5a antagonist groups $(P<0.01)$.

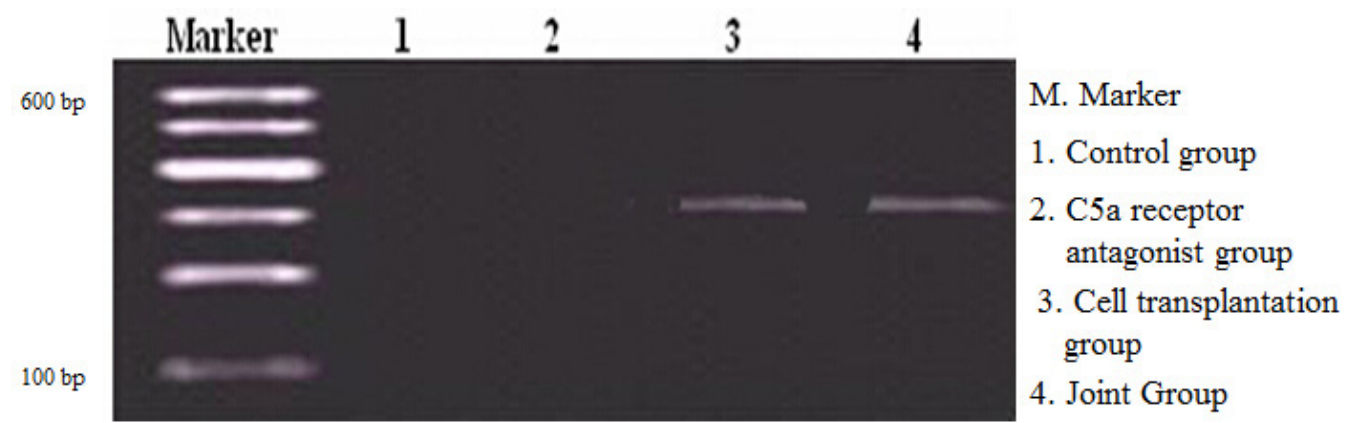

Figure 3. SRY gene expression in spinal cord tissue from the different treatment groups at 4 weeks after injury.

\section{SEP and MEP measurements}

Subsequent to the establishment of the spinal cord injury model, SEP and MEP measurements showed that the evoked potential waves disappeared completely in all groups. At 8 weeks post-injury, SEP and MEP slightly recovered in the control group, while all the treatment groups showed a significant recovery with increased wave amplitude. The SEP latency and amplitude of each group are shown in Tables 3 and 4. The transplantation and C5a antagonists groups showed significant differences from control $(P<0.05)$. The combination group showed a 
highly significant difference from control $(P<0.01)$. These differences suggested that the signal conduction pathway from the rear limbs to the cortex had recovered, particularly in the combination group.

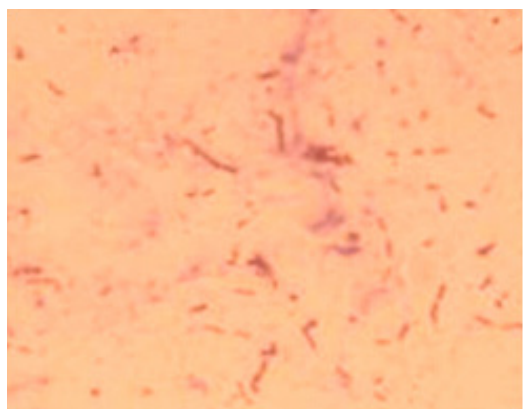

A

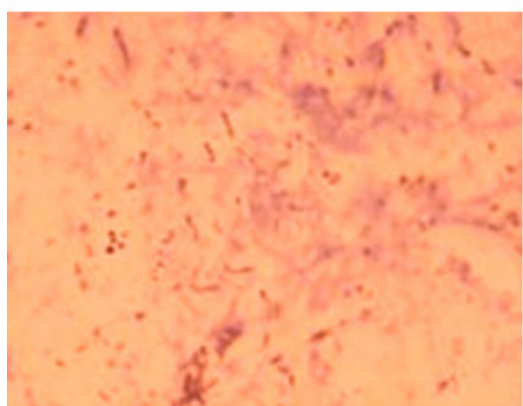

$\mathrm{C}$

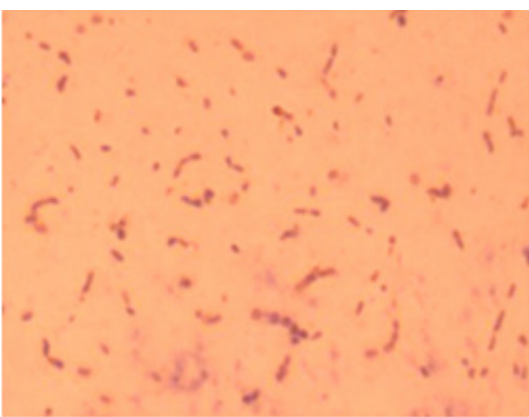

B

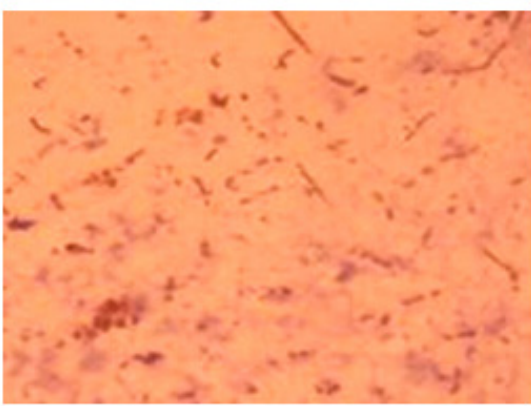

$\mathrm{D}$

Figure 4. A. HRP staining at 8 weeks after injury in the control group (200X); B. HRP staining at 8 weeks after injury in cell transplantation group (200X); C. HRP staining at 8 weeks after injury in the C5a receptor antagonist (200X). D. HRP staining at 8 weeks after injury in the cell transplantation and C5a receptor antagonist combination group (200X).

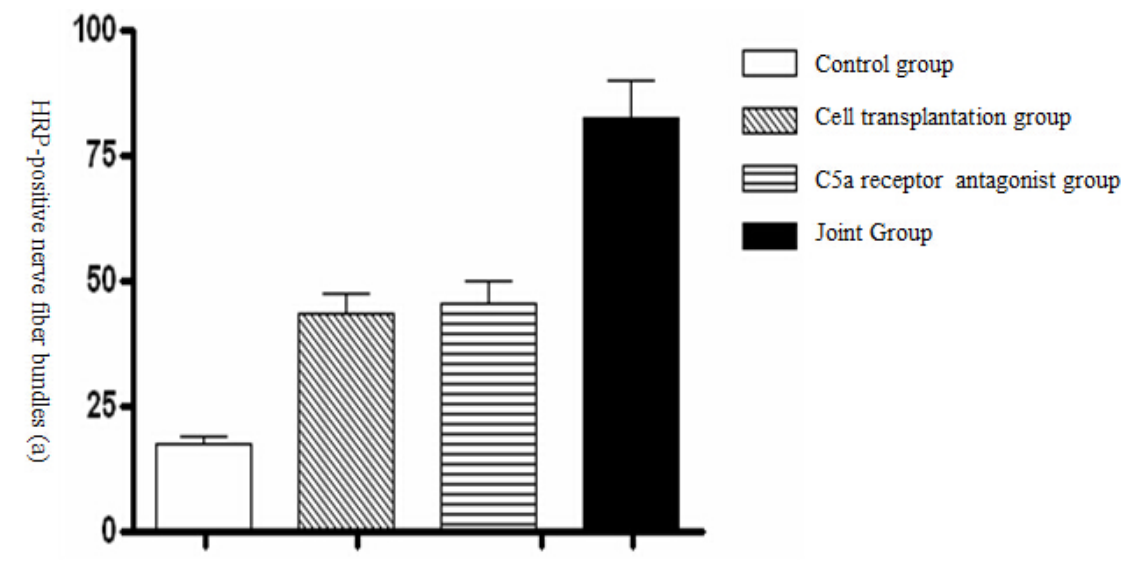

Figure 5. Number of HRP-positive nerve fibers measured at 8 weeks after injury. 
Table 3. Somatosensory evoked potential (SEP) testing in each group 8 weeks after injury.

\begin{tabular}{lcc}
\hline Treatment group & Latency period $(\mathrm{ms})$ & Amplitude $(\mu \mathrm{V})$ \\
\hline Control & $35.262 \pm 1.376$ & $1.348 \pm 0.146$ \\
Cell transplantation & $26.354 \pm 1.045^{\#}$ & $1.742 \pm 0.197^{\#}$ \\
C5a receptor antagonist & $25.972 \pm 0.986^{\#}$ & $1.738 \pm 0.102^{\#}$ \\
Joint group & $14.672 \pm 0.847^{\star}$ & $2.115 \pm 0.223^{\star}$ \\
\hline
\end{tabular}

Compared with control group: ${ }^{\mathrm{P}}, 0.05 ; \stackrel{\wedge}{ } \mathrm{P}<0.01$.

Table 4. Motor evoked potential (MEP) testing in each group 8 weeks after injury.

\begin{tabular}{lcc}
\hline Treatment group & Latency period $(\mathrm{ms})$ & Amplitude $(\mathrm{mV})$ \\
\hline Control & $15.642 \pm 0.436$ & $1.684 \pm 0.164$ \\
Cell transplantation & $11.942 \pm 0.327^{\#}$ & $2.432 \pm 0.295^{\#}$ \\
C5a receptor antagonist & $11.928 \pm 0.336^{\#}$ & $2.454 \pm 0.282^{\#}$ \\
Joint group & $7.813 \pm 0.204^{\star}$ & $4.162 \pm 0.302^{\star}$ \\
\hline
\end{tabular}

Compared with control group: ${ }^{P}<0.05 ; \Delta P<0.01$.

\section{DISCUSSION}

Spinal cord injury is a serious injury that often causes disability or sequelae such as paralysis. Spinal cord injury therapy remains one of the most difficult medical challenges. It was previously believed that central nervous system tissues could not regenerate. However, recent studies have found that a change in the microenvironment of the injured spinal cord enables axons to regenerate (Lepore et al., 2006; Zhan et al., 2008). Schwann cells are the main structural and functional cells in the peripheral nervous system and play an important role in the recovery from injury, regeneration, and repair of peripheral nerves. They form the myelin sheath of peripheral nerve fibers. Schwann cells, which were previously in a resting state, start proliferating in response to spinal cord injury. They become involved in the phagocytosis of denatured axons and myelin sheaths, modification of cell structures, upregulation of adhesion factors, synthesis and release of bioactive factors, and provision of the necessary matrix for axon regeneration. All of these contributions produce a favorable environment for post-injury neural repair (Saberi et al., 2008; Ban et al., 2009; Chi et al., 2010). Implanted Schwann cells can bridge the nerve tissues in the injured area and form myelin sheaths to cover the regenerated axons. This stimulates the remaining axons to grow side branches and increase the connections with other axons to compensate for the lost axons, thereby facilitating spinal recovery. In addition to forming a myelin sheath outside axons, Schwann cells can secrete a number of neurotrophic factors, including neurotrophin-3, nerve growth factor, brain-derived neurotrophic factor, ciliary nerve growth factor, and fibroblast growth factor. These enhance the survival and differentiation of neurons, support and induce the formation of axons and dendrites, and reduce the scar formation of glia after spinal cord injury.

Spinal cord injury can be primary or secondary. Secondary injury is the main type of spinal cord pathology injury (Amar and Levy, 1999; Hausmann, 2003). Apoptosis has critical functions in secondary spinal cord injury. Apoptosis mainly occurs in oligodendrocytes, whereas neurons in gray matter do not undergo apoptosis (Wang et al., 2004; Morizane et al., 2012). Inflammatory reactions are also important in secondary spinal cord injury. Certain inflammatory reactions facilitate repair, whereas excessive inflammation increases oligodendrocytes apoptosis and worsens the spinal cord injury, thereby affecting the later functional recovery (Kwon et al., 2004). The complement system also plays an important role in the inflammatory reaction. After central nervous system 
injury, complements are either produced by invading or endogenous immune cells, or enter the central nervous system through an impaired blood-brain barrier. This significantly increases the numbers and activity of complements, thereby increasing inflammation (Klos et al., 2009). The complement fragment $\mathrm{C} 5 \mathrm{a}$ is regarded as the most potent complement fragment in inflammatory reactions (Guo and Ward, 2005) and it most likely mediates the inflammatory reaction at the early stage of injury. C5a receptor antagonists effectively block this process.

To summarize, in the current study, we combined a C5a receptor antagonist together with Schwann cell transplantation to study the joint effect on the neural function recovery after spinal cord injury. The results showed that this combination was significantly better, histologically and functionally, than either therapy alone.

\section{ACKNOWLEDGMENTS}

We express our sincere gratitude to Dr. Jingjian Ma from the Department of Neurosurgery, General Hospital of Tianjin Medical University, China for revising this manuscript.

\section{REFERENCES}

Albin RL and Mink JW (2006). Recent advances in Tourette syndrome research. Trends Neurosci. 29: 175-182.

Amar AP and Levy ML (1999). Pathogenesis and pharmacological strategies for mitigating secondary damage in acute spinal cord injury. Neurosurgery 44: 1027-1039.

Ban DX, Kong XH, Feng SQ, Ning GZ, et al. (2009). Intraspinal cord graft of autologous activated Schwann cells efficiently promotes axonal regeneration and functional recovery after rat's spinal cord injury. Brain Res. 1256: 149-161.

Braisted JE, Catalano SM, Stimac R, Kennedy TE, et al. (2000). Netrin-1 promotes thalamic axon growth and is required for proper development of the thalamocortical projection. J. Neurosci. 20: 5792-5801.

Chi GF, Kim MR, Kim DW, Jiang MH, et al. (2010). Schwann cells differentiated from spheroid-forming cells of rat subcutaneous fat tissue myelinate axons in the spinal cord injury. Exp. Neurol. 222: 304-317.

Chu D, Bakaeen FG, Shenaq SA, Ribati M, et al. (2007). Open-heart operations in patients with a spinal cord injury. Am. J. Surg. 194: 663-667.

De Vries M and Cooper HM (2008). Emerging roles for neogenin and its ligands in CNS development. J. Neurochem. 106: 1483-1492.

Fehlings MG and Sekhon LH (2001). Acute interventions in spinal cord injury: what do we know, what should we do? Clin. Neurosurg. 48: 226-242.

Finch AM, Wong AK, Paczkowski NJ, Wadi SK, et al. (1999). Low-molecular-weight peptidic and cyclic antagonists of the receptor for the complement factor C5a. J. Med. Chem. 42: 1965-1974.

Guo RF and Ward PA (2005). Role of C5a in inflammatory responses. Annu. Rev. Immunol. 23: 821-852.

Haku T, Okuda S, Kanematsu F, Oda T, et al. (2008). Repair of cervical esophageal perforation using longus colli muscle flap: a case report of a patient with cervical spinal cord injury. Spine J. 8: 831-835.

Hausmann ON (2003). Post-traumatic inflammation following spinal cord injury. Spinal. Cord. 41: 369-378.

Klos A, Tenner AJ, Johswich KO, Ager RR, et al. (2009). The role of the anaphylatoxins in health and disease. Mol. Immunol. 46: 2753-2766.

Kwon BK, Tetzlaff W, Grauer JN, Beiner J, et al. (2004). Pathophysiology and pharmacologic treatment of acute spinal cord injury. Spine. J. 4: 451-464.

Lepore AC, Neuhuber B, Connors TM, Han SS, et al. (2006). Long-term fate of neural precursor cells following transplantation into developing and adult CNS. Neuroscience 142: 287-304.

Morizane K, Ogata T, Morino T, Horiuchi H, et al. (2012). A novel thermoelectric cooling device using Peltier modules for inducing local hypothermia of the spinal cord: The effect of local electrically controlled cooling for the treatment of spinal cord injuries in conscious rats. Neurosci. Res. 72: 279-282.

Pallini R, Vitiani LR, Bez A, Casalbore P, et al. (2005). Homologous transplantation of neural stem cells to the injured spinal cord of mice. Neurosurgery 57: 1014-1025.

Papastefanaki F, Chen J, Lavdas AA, Thomaidou D, et al. (2007). Grafts of Schwann cells engineered to express PSA-NCAM promote functional recovery after spinal cord injury. Brain 130: 2159-2174. 
Pearse DD, Sanchez AR, Pereira FC, Andrade CM, et al. (2007). Transplantation of Schwann cells and/or olfactory ensheathing glia into the contused spinal cord: Survival, migration, axon association, and functional recovery. Glia 55: 976-1000.

Saberi H, Moshayedi P, Aghayan HR, Arjmand B, et al. (2008). Treatment of chronic thoracic spinal cord injury patients with autologous Schwann cell transplantation: an interin report on safety considerations and possible outcomes. Neurosci. Lett. 443: 46-50.

Wan H, Lin Y, Sun MZ, Zhang YZ, et al. (2003). Schwann cells in vitro before transplantation brain. Zhonghua Shenjing Waike Zazhi 19: 213-215.

Wang CS, Shi ZB, Wang KZ and Chen JC (2004). Effects on neuronal apoptosis after spinal cord injury olfactory ensheathing cell transplantation. Zhongguo Linchuang Kangfu 8: 7982-7983.

Weaver FM, Burns SP, Evans CT, Rapacki CT, et al. (2009). Provider perspectives on soldiers with new spinal cord injuries returning from Iraq and Afghanistan. Arch. Phys. Med. Rehabil. 90: 517-521.

Young W (2002). Spinal cord contusion models. Prog. Brain Res. 137: 231-255.

Zhan R, Chen S, Wang W, Long H (2008). Effects of Nogo-neutralizing antibody and neurotrophin-3 on axonal regeneration following spinal cord injury in rat. Neural. Regen. Res. 3: 1319-1323. 